MINERALOJIA DE CHILE.-Nuevos dscubrimientos hechos en el reino mineral de Chile $i$ de las repúblicas vecinas;-conocimiento de nuevas especies minerales, de nuevas localidades en que se han hallado los minerales mas raros, $i$ do nuevos análisis quie se lian hecho de los minerales conocidos;-trabajos pjecutados en el laboratorio del Instituto Nacional i estracto de las revistas cientificas estranjer:as. (Śegundo apéndice a la scgunda edicion de la Mineralojía de don (1. Domeyko.)

\title{
ADVERTENCIA.
}

Conlorme a lo que me he propuesto en el prólogo a la segunda edicion de mis Elementos de Mineralojía impresas en 1860 en Sintiago, voi a publicar este segundo apéndice al Reino mineral de Chile que en aquel tiempo por la primera vez me he atrevido a compendiar al fin del mencionado libro. En este segundo apéndice le procurado incluir mis propios trabajos analíticos i los de mis alumnos como tambien los de los quimicos i mineralojistas estranjeros: trabajos referentos a los productos minerales de Chile i de las repúblicas vecinas.

Mi único objeto ha sido ensanchar de este modo el conocimiento especial de la mineralojía de Chtle, acopiando poco a poco los datos que puedan servir algun dia para una descripcion mas completa de la naturaleza mineral del pais, i. con este mismo objeto me propongo con tinuar mis investigaciones, aprovechándome tambien de los trabajos que se publicarán en otras partes del mundo con referencia a Chile.

\section{Minerales metálicos.}

MOLIBDENO.

Molmbdena sulfúrea - En varias localidades i en cantidad conside rable se ha hallado este mineral en Chile $i$ en Bolivia; especialmente: 
ALDO CASALI es Ingeniero Civil de Minas de la Universidad de Chile y tiene el grado de Master of Science en Metalurgia Extractiva de la Universidad de Utah, EE.UU. Durante su carrera de más de 25 años se ha desempeñado como académico y como consultor de procesos, en el área de procesamiento de minerales. Actualmente es Profesor Asociado y Director del Departamento de Ingeniería de Minas de la Universidad de Chile. Es autor o coautor de más de 40 publicaciones internacionales, ha participado en más de 15 proyectos de investigación y es evaluador de proyectos de investigación para CONICYT y para diversas universidades nacionales. Ha participado en el comité organizador de 6 congresos internacionales y se ha desempeñado en diversas ocasiones como Chairman de sesiones de congresos internacionales y como referee de revistas y congresos internacionales en su especialidad. 


\section{DOMEYKO Y LA MINERALOGÍA EN CHILE Aldo Casali}

Ignacio Domeyko, el padre de la minería chilena, cuyo principal objetivo declarado era "difundir nuevas luces sobre el ramo de la minería, que forma con la agricultura, la principal riqueza de Chile", entrega este excelente aporte sobre la riqueza mineral de Chile y sus países vecinos. Nombrado Delegado Universitario en 1852, organiza la Facultad de Ciencias Físicas y Matemáticas donde desde 1853 se comienza a formar a los ingenieros civiles y de minas del país. Desde su posición como Secretario (lo que hoy corresponde al Vicedecano) de la recién creada facultad, Domeyko crea y organiza el plan de estudios de la carrera de ingeniería de minas, la primera del país, de la que egresan por primera vez 4 ingenieros el año 1856. Ignacio Domeyko, además, fue Rector de la Universidad de Chile durante 3 períodos, desde 1867 hasta 1883.

El aporte de Ignacio Domeyko al desarrollo de la minería nacional es extraordinario. A partir de la exploración del territorio contribuye significativamente a su conocimiento geológico y mineralógico, propone al gobierno nuevas leyes de fomento y estímulo a la industria minera, y contribuye desde la universidad y por medio de la enseñanza superior de la ingeniería de minas a la renovación de las técnicas de explotación minera. En todas estas acciones es perfectamente posible ver las bases de lo que es hoy la principal actividad económica del país y su permanente fuente de riquezas y desarrollo.

El destacado sabio lituano (territorio polaco en la época de su nacimiento), en el trabajo que se presenta en esta edición extraordinaria de la revista Anales de la Universidad de Chile, contribuye describiendo una serie de minerales presentes en Chile, utilizando para ello tanto sus propios trabajos y los de sus alumnos, así como también los publicados por otros investigadores extranjeros. Cómo no reparar en que sobre nuestro principal producto, el cobre, afirma que: "Es tan abundante i tan variada en especies la mineralogía de cobre en Chile que no pasa un año sin que se descubra algo de nuevo i de notable en esta familia de minerales".

A la luz de la realidad actual del país -primer productor mundial de cobre (con más del 34\% de la producción mundial) y entre los 5 principales productores mundiales de plata, molibdeno, renio, nitratos, litio y yodo- el presente y el futuro de Chile están sin duda ligados a la minería. La naturaleza ha sido generosa con el país, colocando en su territorio muchas riquezas minerales. Su conocimiento, descubrimiento y explotación tienen una base reconocible en la información mineralógica a la que el trabajo de este gran sabio contribuyó de manera formidable. 
MINERALOJIADE CHILE. -Nuevos descubrimientos hechos en el reino mineral de Chile i de las repúblicas vecinas;-conocimiento de nuevas especies minerales, de nuevas localidades en que se han hallado los minerales mas raros, i de nuevos análisis que se han hecho de los minerales conocidos; -trabajos ejecutados en el laboratorio del Instituto Nacional i estrado de las revistas científicas estranjeras. (Segundo apéndice a la segunda edicion de la Mineralojía de don I. Domeyko.)

\section{ADVERTENCIA.}

Conforme a lo que me he propuesto en el prólogo a la segunda edicion de mis Elementos de Mineralojía impresas en 1860 en Santiago, voi a publicar este segundo apéndice al Reino mineral de Chile que en aquel tiempo por la primera ves me he atrevido a compendiar al fin del mencionado libro. En este segundo apéndice he procurado incluir mis propios trabajos analíticos i los de mis alumnos como tambien los de los químicos i mineralojistas estranjeros: trabajos referentes a los productos minerales de Chile i de las repúblicas vecinas.

Mi único objeto ha sido ensanchar de este modo el conocimiento especial de la mineralojía de Chile, acopiando poco a poco los datos que puedan servir algun dia para una descripcion mas completa de la naturaleza mineral del pais, i con este mismo objeto me propongo continuar mis investigaciones aprovechándome tambien de los trabajos que se publicarán en otras partes del mundo con referencia a Chile.

MINERALES METÁLICOS.

\section{Molibdeno.}

MOLIBDENA SULFÚREA - En varias localidades i en cantidad considerable, se ha hallado este mineral en Chile i en Bolivia; especialmente:

1. ${ }^{\circ}$ En la Cordillera de las Condes, quebrada de Duarte, a mucha altura en el interior de los Andes, casi en frente de la capital: amorfa, en hojas mui anchas i mui lustrosas, i en grandes prismas rectos hexajonales cortos, de 3 a 4 centímetros de diámetro, acompañada por la turmalina negra i felspato. Con facilidad atacable por los ácídos; deja en ellos un abundante residuo blanco.

$2 .^{\circ}$ En Peralillo, hacienda de la Punta, a pocas leguas al noroeste de Santiago, en una mina de cobre, llamada Ignoraneia.-amorfa, en masas irregulares, granudas o mas bien escamosas, de color gris azulejo, mui blandas i fácilmente atacables por el ácido nítrico, en el cual deja un residuo blanco como la de las Condes. Su criadero es gris arcilloso i su compañero el cobre piritoso.

3. ${ }^{\circ}$ En Cobija, a unas dos leguas del puerto, cerca de la orilla del mar, en medio de rocas graníticas. Hállase en esta localidad la molibdena sulfúrea unas veces en hojas anchas lustrosas, parecida a la de la Cordillera de las Condes, otras veces en masas amorfas granucias que dejan en el ácido nítrico un residuo amarillo soluble en el amoniaco i la disolucion amoniacal reproduce al agregar ácido nítrico el mismo residuo amarillo. Se halla acompañada por la turmalina negra,, fibrosa.

\section{Tunsteno.}

TUNSTATO DE CAL URANÍFERO. --He recibido de Coquimbo, de una veta que atraviesa rocas graníticas de la quebrada de Talca, a unas cinco o seis leguas al este de la Serena, fragmento de un gran cristal de tunstato de cal. Me aseguran que esta muestra proviene de una veta de cuarzo que hace dos años se esplotaba por cristal de roca; pero en sus inmediaciones se hallan tambien unas antiguas minas ele oro. 
La muestra de que se trata pesa mas de 150 gramos i presenta caras que pertenecen al octaedro; pero al juzgar por la estension de sus caras i el diámetro de la parte fracturada, parece que el cristal entero debia pesar el doble o triple de lo que pesa el fragmento que tengo en mi poder. Las caras son rayadas i tienen lustre de vidrio algo imperfecto pero en la fractura mucho lustre que pasa a lustre de diamante. Nótanse tambien en la fractura cruceros bastante claros aunque interrumpidos. Su color es amarillo apagado algo parduzco, pero su polvo es blanco que tira algo a amarillo. Durera 5.5- al soplete casi infusible.

No es completamente atacable por el ácido nítrico: sometiendo esta mineral a la accion alternativa de este ácido i de amoniaco se obtiene $44 \%$ de residuo sobre el cual ni el ácido ni el amoniaco ejercen accion alguna.

Ejecutando varios análisis del mismo mineral, ya sea por el bisulfato, ya por el carbonato de potasa, he llegado a obtener siempre en ú1timo resultado mas de $5 \%$ de residuo que parece ser ácido tantálico; pero al propio tiempo hallo en el mismo mineral 6 de óxido de urano: -de manera que la composicion de este mineral seria la siguiente

\begin{tabular}{|l|r|}
\hline ácido tunstico (por diferenia) . & 68.75 \\
\hline ácido tantálico (silice) & 5.95 \\
\hline óxido de calcio & 18.65 \\
\hline de urano & 6.20 \\
\hline de hierro & 0.45 \\
\hline de cobre indicio & \\
\hline
\end{tabular}

(Exceptuando las proporciones de cal i de arano que se han podido determinar con mayor exactitud, las de los demas elementos necesitan una investigacion ulterior)

No he podido hasta ahora averiguar la verdadera localidad de donde se ha estraido el mencionado cristal ni he conseguido adquirir mayor cantidad de esta sustancia.

TUNSTATO DE CAL COBRIZO,- El descubrimiento del mineral que acabo de describir me ha dado motivo de volver a examinar el tunstato de cal cobrizo de Llamuco (páj. 52 de mi Minealojía) cuyo análisis i descripcion publiqué hace mas de veinte años. Habiéndome obsequiado el dueto de la mencionada mina señor don Bruno Larrain muestras mas puras de esta especie, las analicé tratando el mineral alternativamente por el ácido nítrico por el amoniaco. Hallo que este tunstato es mucho mas atacable que el anterior i no deja mas que 0.017 de materia silicatada insoluble en el amoniaco. El color de la parte mas pura de este mineral es de un verde parecido al de la variedad mas comun de epidota pistachaí; su lustre es de vidrio que tira al de resina, su polvo amarillento pálido claro, estructura hojosa con cruceros algo imperfectos. Consta segun último análisis de la parte mas pura del mineral de

\begin{tabular}{|l|r|}
\hline ácido tunstico & 72.77 \\
\hline óxido de calcio & 15.45 \\
\hline de cubre & 4.40 \\
\hline de hierro & 2.25 \\
\hline resíduo silicatado. & 1.70 \\
\hline pérdida en el fuego & 1.00 \\
\hline
\end{tabular}

Una muestra del mismo mineral con caractéres esteriores parecidos a los del tunstato de Llamuco me ha sido traida de Baja California por el Injeniero de minas señor Réinold de Corbineau a quien fué obsequiada esta misma muestra por el señor Fouques, director del establecimiento conocido bajo el nombre de Nott1i Beach Metallurgica Morks en San Francisco. Ha sido reconocido este mineral por el señor I. D. Whitney como tunstato de cal cobrizo i su color es algo mas oscuro que el del mineral chileno, pero del mismo lustre i de la misma estructura hojosa que este último.

Para reconocer la identidad de los dos minerales hallados en los dos hemisferios del nuevo continente, desconocidos hasta ahora en el antiguo, he analizado la muestra traida de Baja Ca- 
lifornia por el mismo método que me sirvió para analizar el mineral de Llamuco i la hallo compuesta del modo siguiente:

\begin{tabular}{|l|r|}
\hline ácido tunstico & 62.50 \\
\hline Protóxido de cobre CnO & 9.91 \\
\hline de hierro FO & 3.82 \\
\hline Cal & 10.55 \\
\hline Sílice inatacable, ferruginosa & 13.20 \\
\hline & 99.98 \\
\hline
\end{tabular}

Se ve por consiguiente que en este mineral, una parte de la cal está reemplazada por el óxido de cobre. Se halla acompañada esta especie en California por la turmalina fibrosa negra.

VOLFRAN.-(Distinguen los mineralojistas alemanes entre las diversas especies de volfran que se conocen hasta ahora, dos minerales que llaman el uno Volfranit $\mathrm{RO} . \mathrm{WO}_{3} \mathrm{i}$ el otro Farberit $4 \mathrm{RO}$. $3 \mathrm{WO}_{3}$. Aquel es de lustre metálico ido diamante; es algo mas duro, mas denso i menos fusible que el segundo, i contiene ménos cal i ménos magnesia que este último; al propio tiempo el volfranit no contiene alumina i su polvo es pardo rojizo.)

El volfran de Marococha en el Perú, descrita por Breithaupt bajo el nombre de Glumimit, se acerca por sus caractéres i composicion mas bien al ferberit que al Wolfranit (Neu. Iahrb de Miner. Leonord und Geinitz 1863 p. 650.)

\section{Tántalo.}

El Museo británico posee un hermoso cristal de columbiana, hallado en el granito de Montevideo. Phil. Maj. 1863. 40-42.

\section{Titano.}

HIERROS TITÁNICOS. -El hierro titánico es, segun toda probabilidad, uno de los minerales mas diseminados en el sistema de los Andes de Chile i de las Repúblicas vecinas. Varian mucho su composicion i el criadero en que se halla. Unas veces se encuentra en vetas que atraviesen el granito, con anfibola fibrosa, feispato i cuarzo; otras veces diseminado en medio de pórfidos. Pero tambien hállase con frecuencia en los terrenos de acarreo aurífero, formando gruesos guijarros que acompañan el oro i en arenas que aparecen, ya sea en las playas i embocadura de los rios, ya en el interior del pais.

Entre las diversas variedades de hierro magnético que hasta ahora he tenido la ocasion de examinar, debo citar:

$1 .^{\circ}$ Hierros titánicos no magnéticos.

2. ${ }^{\circ}$ Hierros titánicos magnéticos.

3. ${ }^{\circ}$ Arenas titaníferas.

En jeneral, todas estas variedades -o especies se conocen i se distinguen de los demas minerales metálicos ferrujinosos, $1 .^{\circ}$ por su dureza 5.5 que es superior a la de todos los súlfuros i arseniuros, 2.0 por su color -que por lo comun es negro de hierro por fuera, i gris de acero oscuro por dentro, 3,0 por su infusibilidad, 4 por el color de su polvo que no es ni rojizo como el de hierro olijisto, ni pardo; en fin, por la reaccion característica que se descubre al soplete.

He aquí algunas especies analizadas:

HIERRO TITÁNICO de SAN JUAN (provincias arjentinas).-En pequeñas masas irregulares, con indicio de cristalization cuya forma parece derivar del romboedro; color gris mui oscuro; estructura casi compacta; fractura desigual, que pasa a conchoidea; polvo gris metálico. No es magnético. Dur. 5.5. Es fácilmente atacable por el ácido muriático. Sus compañeros son: el feispato 
ortoclasia de dos cruceros mui fáciles, i la mica. Proviene de las minas de plata de la Huerta en San Juan. Consta de

\begin{tabular}{|l|c|}
\hline Sesquióxido de hierro & 70,15 \\
\hline protozido de hierro & 10,50 \\
\hline ácido titánico & 11,60 \\
\hline sílice (cuarzo) & 2,56 \\
\hline cal 0.28, magnesia 0.22 & 0,50 \\
\hline & 99,31 \\
\hline
\end{tabular}

Se parece, pues, por su composicion al hierro titánico de Uldewalla, i al de Aschaffenburg, analizado por Kobel.

HIERRO TITÁNICO de VALDIVIA. -Entre los minerales que acompañan el oro en los lavaderos de la provincia de Valdivia, halló don Federico Philippi granos i fragmentos de cristales, algunos cristales bastante completos, pertenecientes a dos especies de hierro titánico: unos no magnéticos o dotados de virtud magnética débil, i otros magnéticos.

El hierro no magnético de dichos lavaderos es enteramente parecido al de San Juan: solamente la forma de sus cristales es mas visible: sus caras lustrosas son truncamientos en los vértices del romboedro i otras, laterales, análogas a las formas del hierro olijisto. Esta especie es, por consiguiente, como la de San Juan una variedad de ilmenia,

En la fractura se ven cruceros paralelos a los truncamientos en, los vértices; la estructura trasversal granada. Es completamente atacable por el ácido muriático en ebullicion.

El compañero del anterior es hierro magnético en cristales octaédricos, i en fragmentos irregulares.

Este último no tiene sino \% de ácido titánico, miéntras que el anterior, no magnético, consta de

\begin{tabular}{|l|r|}
\hline Sesquióxido de hierro. & 96.87 \\
\hline ácido titánico & 3.13 \\
\hline
\end{tabular}

\section{HIERRO TITÁNICO MAGNÉTICO DE LAS INMEDIACIONES DE TUPUNGTO.}

Debo el conocimiento de este mineral a mi amigo Dr. Sazie.

Es amorfo, en pequeñas masas en medio de una roca granítica, acompañado por la ortoclasia, anfíbola fibrosa, i epídota.

Su color es parecido al de hierro no magnético de San Juan, pero el de Tupungato es mui magnético i de fractura hojosa gruesa de dos cruceros imperfectos, de los cuales uno es bastante lustroso i el otro ménos claro, interrumpido: el ángulo que forman parece aproximarse a $119^{\circ}$. Fractura trasversal casi compacta, en partes concoidea pequeña. Dar. 5. Su polvo es de un gris metálico muí oscuro; completamente atacable por los ácidos. Consta de

\begin{tabular}{|l|c|}
\hline protóxido de hierro. & 31.02 \\
\hline sesquióxido de hierro & 63.30 \\
\hline ácido titánico & 6.07 \\
\hline
\end{tabular}

ARENA TITÁNICA DE MAGALLÁNES.- Esta arena me ha sido mandada por el antiguo Gobernador de la Colonia chilena de Magallanes, don Jorje Schytte, i proviene de la playa de Punta arenas, cerca de la boca del Rio de las Minas, rio que toma su nombre por los afloramientos de las capas de carbon fósil que se hallan en su orilla.

Esta arena es de grano mui pequeño, negro, lustroso, de lustre metálico, no redondo pero de aristas i esquinas embotadas, i de tamaño casi igual. Hállanse tambien mezcladas -en medio de esta arena negra, metálica, granos igualmente pequeños de cuarzo sin color i de cuarzo amarillento.

Pero lo que hai de mas particular en esta arena -es que, entre sus granitos casi iguales i del mismo color, unos son mui magnéticos i otros no magnéticos: de manera que por medio de un 
iman con facilidad se separan los unos de los otros i se obtienen dos arenas casi del mismo aspecto pero de composicion mui diferente. Sin embargo la que es magnética parece tener color mas negro i ménos lustre que la otra. Ambas son completamente atacables por ebullicion prolongada en ácido clorhídrico concentrado: la primera se disuelve sin formar residuo alguno, i la no magnética deja en el ácido 8 a $9 \%$ de materias cuarzosas.

Analizadas las dos especies separadamente por el bisulfato i, para la determinacion de las proporciones en que se hallan los dos óxidos, por el ácido muriático en los matraces llenos de ácido carbónico, obtuve para la composicion de estas dos especies lo siguiente:

\begin{tabular}{|l|c|c|}
\hline & arena no magnética & arena magnética. \\
\hline protóxido de hierro & 15.8 & 29.7 \\
\hline sesquióxido de hierro & 61.5 & 49.7 \\
\hline ácido titánico & 22.8 & -19.2 \\
\hline cal & & 0.9 \\
\hline magnesia & ${ }^{1} 100.1$ & 1.0 \\
\hline \multicolumn{2}{|l|}{} \\
\hline
\end{tabular}

Ambas provienen la destruccion de las rocas de cristalizacion de los terrenos litorales, i presentan mucha analojía en cuanto a su composicion con las dos especies de hierro titánico de Areudal, analizadas por Mozander i citadas por Berthier en su Tratado de Ensayes, p270.-

Arenas parecidas se hallan en las playas de Concon, en Valparaiso i muchas otras en Chile.

ARENA TITÁNICA DE COBIJA.- Es tambien mui interesante por sus caractéres mineralójicos una arena titánica mui magnética de Cobija: de grano pequeño, redondeado, poco lustroso, casi todo del mismo tamaño. Esta arena, parecida por su aspecto a la pólvora de caza, se halla mezclada con pequeños granitos de cuarzo parecidos a los de la de Magallánes. Analizada en el laboratorio del Instituto, se halló compuesta de

\begin{tabular}{|l|l|}
\hline ácido titánico & 14.10 \\
\hline protóxido i sesquióxido de hierro (por diferencia) & 85.90 \\
\hline
\end{tabular}

Segun el señor Latrille, residente en Cobija, a quien debo muestras de este mineral, proviene esta arena de un lugar situado a unas treinta leguas de Cobija i trece a catorce de Calaina. En este lugar se ve cubierto un estenso plano inclinado con esta arena, en cuya superficie se ve tambien capa delgada de arena cuarzosa. El viento reinante que remueve continuamente las dos, cambia continuamente el aspecto i el color del llano, sobre el cual moviéndose masas considerables de acarreo producen cierto ruido estraño que dan lugar a varios cuentos entre los indíjenas.

\section{Manganesa.}

Es notable que en ninguna parte todavía se ha hallado en la inmensidad de los depósitos metalíferos de Chile algun óxido de manganeso cristalizado o fibroso que son tan comunes en el antiguo continente. Pero aparece en varios lugares de Chile mineral de bióxido de manganesa de color gris metálico que contiene proporciones considerables, mui variables de sílice i es anhidro o mui poca agua tiene.

1. ${ }^{\circ}$ Así muestras de minerales de esta naturaleza traidas del Desierto de Atacama, negras por fuera i de gris de acero en la fractura recien hecha, tienen estructura granuda de grano mui fino, igual, mui homojéneo i fractura plana que tira a concoidea ancha. El polvo de este mineral de Atacama es gris metálico, exhala mucho cloro si se le hace hervir con ácido clorhídrico i deja en este ácido residuo blanco de silice no jelatinosa.

Analizada una muestra de dicho mineral en el laboratorio del Instituto dió; 


\begin{tabular}{|l|c|}
\hline bióxido de manganesa & 81.0 \\
\hline óxido de cobre & 2.0 \\
\hline sesquióxido de hierro & 0.4 \\
\hline magnesia & 0.6 \\
\hline sílice & 8.6 \\
\hline agua & 3.0 \\
\hline
\end{tabular}

2. ${ }^{\circ}$ Otro mineral análogo, hallado en la provincia de Santiago, de color gris metálico con ménos lustre que el anterior i de grano grueso, soluble en el ácido muriático con desarrollo de cloro, deja en este ácido $42 \%$ de sílice i no contiene mas que $2.50 \%$ de hierro i $2 \%$ de agua.

\section{Hierro.}

METEOROLITA DE LA SIERRA DE CHACO.- Grandes masas de acrolita se han hallado en el desierto de Atacama a mas de un grado de latitud al sur de Imilac (lugar de donde viene el famoso hierro meteórico de Atacama), i a unas cuarenta leguas al nordeste del puerto de Taltal, en frente de la Sierra de Chaco. Una casualidad me ha dado a conocer últimamente el nombre que los cateadores de minas dan a lugar que segun toda probabilidad es la verdadera localidad en que se han hallado esas masas de aerolita i es: Quebrada de Vaca Muerta, doce leguas de la caleta de Guanillo.

Esta aerolita es mui notable por la proporcion mui grande de hierro niquelifero diseminado en su masa, proporcion que en los trozos enteros no oxidados llega a $39 \%$ : lo que dió motivo a G. Rose de llamar esta aerolita ferrosiderita. La parte metálica consta de 88.9 de hierro i 11.1 de niquél. Se diferencia notablemente esta aerolita de las demas por la composicion de la masa no metálica, la cual consta, en parte, de un polvo que se atrae por el iman i, en su mayor parte, de materia en que no ejerce accion alguna el iman. Esta última contiene 11.84 de protosúlfuro de hierro i 88.26 de materias silicatadas, en cuya composicion entra un trisilicato de hierro i de manganesio inatacable por los ácidos. En medio de esta masa se ve tambien diseminada olivina hojosa la cual en la parte que no se halla todavía tocada por la accion del aire es de color negruzco, debido este color al súlfuro de hierro interpuesto entre sus hojillas, (o talvez a las hojillas mui deladas de hierro niquelifero) i en la parte de la aerolita mas espuesta a la accion del aire es esta oliviea de color amarillento. Segun G. Rose el mineral hojoso de la aerolita es pyroxena. En cuanto al polvo magnético es decir a la parte de la masa que se deja reducir a polvo impalpable i es magnética, se ha reconocido que en esta parte hai ménos súlfuro de hierro que en el polvo magnético i en ella quizas se halla tambien hierro oxidulado i algo de hierro carburado no maleable.

Se han hallado en la misma localidad trozos de aerolita, o aerolitas enteras de todo tamaño, desde el peso de pocos gramos, hasta el de mas de 20 kilógramos. La densidad de ellas varia desde 5.64 hasta 4.10. Esta última corresponde a unos trozos de aerolita mui oxidada i en la cual la proporcion de hierro metálico no pasa de $12 \%$ en la parte esterior de la piedra.

La descripcion detallada de esta aerolita se halla en los Anales de la Universidad de Chile, año de 1865 i en los Anales de Afinas de Paris, año de 1864, I. V. 3 entr. p. 431.

DOS NUEVAS ESPECIES DE HIERRO METEÓRICO DE CHILE.- A mas del hierro meteórico de Imilac (Atacama) que se halla en todos los grandes Museos europeos, he analizado dos nuevas especies de hierro meteórico halladas en Chile pero en localidades desconocidas hasta ahora.

$1 .^{\circ}$ Una de ellas hace parte de la hermosa coleccion de minerales i curiosidades del scñor Lüders en Valparaiso i fué comprada en un remate de minerales chilenos en esta misma ciudad. La meteorita entera pesaba mas de 7 kilógramos, i tenía forma mui irregular algo achatada con convexidades i hundimientos en su superficie. Por fuera tiene color negro en partes parduzco i la superficie algo alizada, en parte con un poco de lustre.

Esta meteorita es una masa metálica en que ni a la simple vista, ni aun mediante un lente, no se descubre el mas pequeño indicio de materias silicatadas i en esto se diferencia mucho del men- 
cionado hierro meteórico de Imilac (Atacama) el cual tanto en la superficie como en el interior presenta pequeñas masas de olivina que tienen 1 a 2 centímetros de diámetro i llenan los huecos de la masa metálica.

El hierro meteórico de la coleccion del señor Lüders es bastante maleable i de mucha tenacidad. Gran trabajo costó para partirlo cuando dicho señor ha tenido la bondad de obsequiarme un fragmento de esta meteorita. En su fractura no se descubrió sino unas pequeñas concavidades cubiertas interiormente de materia ocrácea i su contextura apareció mas bien fibrosa o compacta que granuda. Es fácilmente soluble en el ácido muriático diluido sin desarrollo del menor indicio de hidrójeno sulfurado i no deja sino un pequeño residuo de fosfuro (schreibersite) i de materia silicatada inatacable. Consta de

\begin{tabular}{|l|c|}
\hline hierro & 87.17 \\
\hline niquel & 8.75 (sin caballo) \\
\hline materia silicatada & 2.40 \\
\hline fosfuro de hierro & 1.42 \\
\hline & 99.74 \\
\hline El mencionado fosfuro hallé compuesto de & \\
\hline hierro & 65.0 \\
\hline niquel & 26.3 \\
\hline fósforo & 8.7 \\
\hline
\end{tabular}

Es, pues, una masa de hierro niquelífero una de las mas puras que se conocen. El fragmento que debo a la jenerosidad del señor Lüders pesa 2922 gramos i su densidad es de 6.1 a 6.24 (Ter. 14\%)

$2 .^{\circ}$ La segunda especie de hierro meteórico viene de las inmediaciones de Santiago. Me la trajo un hombre del campo creyendo que era de plata o de algun metal precioso i me aseguraba, que de este metal se hallaban grandes trozas desparramados en la falda de un cerro, de la Cordillera de la Dehesa unas ocho a nueve leguas de la capital $\left({ }^{1}\right)$.

Esta meteorita es de forma todavía mas irregular que la anterior: por fuera negra con indicio de lustre; en su superficie tiene concavidades i huecas bastante grandes, en parte como indicio de cristalizacion. Por dentro es mui homojénea, lustrosa, de contestura granuda, de grano mui firme, sin el menor indicio de materias terrosas o silicatadas. Se achata debajo del martillo i es tan tenaz como la anterior. Completamente soluble en el ácido muriático, sin desarrollo de hidrójeno sulfurado. Consta de

\begin{tabular}{|l|l|}
\hline hierro & 86.2 \\
\hline niquel & 14.1 (no contiene cobalto) \\
\hline
\end{tabular}

Esta materia no se puede equivocar por sus caracteres esteriores ni por su composicion con ninguna de las de hierro meteórico halladas hasta ahora en Chile.

\section{Cobalto, Niquel.}

POLYARSENIURO DE COBALTO NIQUEL I HIERRO DE PUNTA BRAVA- El arseniuro de cobalto es el que con mayor frecuencia acompaña los minerales arsenicales de plata en Tres Puntas, Cabeza de Vaca, Punta Brava, etc. Este arseniuro de las minas de plata contiene casi siempre proporcion notable de niquel la cual en el arseniuro de la Emilia pasa de 2\% (Mineralojía, p. 102.)

Un mineral de la misma especie mui rico en plata nativa i que contiene 11 \% de níquel, se ha hallado en una veta de plata en Punta Brava. Es de color gris mas oscuro que el Cobalto blanco de Cabeza de Vaca i su estructura es granuda de grano grueso. Es lustroso en la fractura recien hecha i pierde mui pronto su lustre por el contacto de aire.

Analizado en el laboratorio del Instituto dió para su composicion

$1 \mathrm{Al}$ dia siguiente de haber convenido conmigo llevarme al lugar de donde habia traido la muestra desapareció el hombre i no he podido hasta ahora descubrir su paradero. 


\begin{tabular}{|l|r|r|}
\hline & & at. \\
\hline arsénico & 60.3 & $(13)$ \\
\hline cobalto & 15.8 & \\
\hline níquel & 11.4 & 9 \\
\hline hierro & 6.2 & \\
\hline plata, & 3.2 & \\
\hline
\end{tabular}

Es, pues, un sesquiarseniuro de Cobalto, níquel i hierro (Co. Ni. F $)^{2} \mathrm{Av}^{3}$. Debo el conocimiento de esta especie a don Leonidas Garcia.

NUEVOS DESCUBRIMIENTOS DE COBALTO.- De varias minas recien descubiertas en la provincia de Atacama los mineros han traído muestras de minerales mui rico de cobalto gris i de cobalto blanco acompañados de cobalto rojo. La mina que en mayor abundancia ha producido estos minerales es la de Pabellon, situada a poca distancia del establecimiento de amalgamacion del mismo nombre, perteneciente a los señores Mandiola en el valle de Copiapó. De la misma mina se han estraido cantidades considerables de un mineral amorfo poco homojéneo en partes terroso en partes granudo, duro i de contestura cristalina, de color rojo mas oscuro que el de arseniato comun de cobalto, con manchas amarillentas, pardas i ocráceas. Este mineral contiene arseniato de cobalto, de níquel, de hierro i de cal, de composicion mui variable i se ven tambien en la misma masa de mineral, venillas de arseniato de cobalto mas puro en agujitas. Sometida al examen la parte del mineral menos heterojónea posible, de color rojo i no apagado que tira algo a rojo cereza, he obtenido para su composicion:

\begin{tabular}{|c|c|}
\hline acido arsénico & 38.8 \\
\hline protózido de cobalto. & 16.0 \\
\hline de niquel & 10.5 \\
\hline de hierro & 2.8 \\
\hline de calcio & 3.9 \\
\hline Agua & 21.2 \\
\hline Criadero & \\
\hline
\end{tabular}

El residuo de calcinacion de este mineral es de color azul de cobalto.

DANAIT O MISPIQUEL COBALTÍFERO DE LAS MINAS DE SAN JOSE (provincia de Santiago). Varias minas de cobalto se han esplorado en el departamento de San José, provincia de Santiago, i entre otras una perteneciente a don Ventura Carvallo, ha producido un cobalto gris tan blanco i lustroso como el mejor mineral de Tunaberg, con una lei de 21, a $22 \%$ de cobalto. Pero la especie mas comun en esta mina es un mispiquel que los mineralojistas ingleses suelen llamar danait, i el cual no contiene mas que 3 a $40 \%$ de cobalt. El mismo mineral hallé en abundancia Forbes a una altitud de 14.000 piés, en el cerro Illampu, en la mina San Baldomero en Bolivia, en cuya mina este mineral es objeto de esplotacion, segun parece bastante lucrativa.

He aquí la composicion de dicho mineral, en las dos mencionadas localidades.

\section{Cobre.}

Es tan abundante i tan variada en especies la mineralojía de cobre en Chile que no pasa un año sin que se descubra algo de nuevo i de notable en esta familia de minerales.

MINERAL ROJO DE LA PUNTA DEL COBRE (Copiapó).- Este mineral recien sacado de la mina tiene los caracteres esteriores de cobre rojo (oxídulo $\mathrm{Cu}^{2} \mathrm{O}$ ) i sin embargo no contiene sino protóxido de cobre i sesquióxido de hierro con 1 de cloro i apenas 2 a $3 \%$ de agua: fue descubierto por el señor Carvajal, Rector del Colejio de Minería en Copiapó. 
La muestra mas pura que me obsequió dicho señor es de color rojo de cochinilla parecido al de subóxido de cobre: pero su raspadura i su polvo tienen color rojo de ladrillo, tanto mas pardo cuanto mas se refriega en un mortero.

$\mathrm{Su}$ lustre es de vidrio que tira algo a resinoso; su estructura compacta que pasa unas veces a hojosa imperfecta, otras veces algo afibrosa. Al soplo da mui poca agua en el matracito i tiñe la llama da azul. Los fragmentos, aun los mas puros, dejándolos por algun tiempo al aire, se cubren de materia verde, terrosa, que es oxicloruro ordinario de cobre i aumentan considerablemente de peso. Esta materia penetra aun en forma de hilitos mui delgados en el interior de la masa roja, la cual tambien con el tiempo se ennegrece. El ácido nítrico mui diluido disuelve este mineral sin ausilio de calor; el polvo toma primero color negro, pero luego desaparece i la disolucion se pone verde azuleja sin la menor produccion de vapor nitroso, de manera que aun todo el peróxido de hierro se disuelve i no queda mas que 6 a $7 \%$ de residuo arcilloso.

El análisis de la parte mas pura i recien fracturada de este mineral me ha dado para su composicion lo siguiente:

\begin{tabular}{|l|c|}
\hline Protóxido de cobre $\mathrm{CuO}$ & 53.4 \\
\hline Sesquiox. de hierro $\mathrm{F}^{2} \mathrm{O}^{3}$ & 33.2 \\
\hline Cobre 0.9 & 1.9 \\
Cloro 1.0 & 0.5 \\
\hline Cal & 6.7 \\
\hline Residuo sihcatadu arcilloso & 3.1 \\
\hline Agua & 98.8 \\
\hline
\end{tabular}

Este mineral es por consiguiente una especie de óxido doble de cobre i hierro anhidro, pues $\operatorname{los} 3 \%$ de agua pertenecen probablemente en parte al oxicloruro formado, en parte (si no en totalidad) al residuo arcilloso. La metamorfosis de este mineral consiste en la absorcion del agua i formacion de atacamita.

En una variedad del mismo mineral hallóse mas de 1 \% de óxido de bismuto.

COBRE NEGRO PURO DE ATACAMA.- Se han hallado en la mina llamada La Lealtad, situada en el departamento de Cobija (Atacama) masas considerables de óxido negro de cobre casi puro, atravesadas por unos hulitos blancos de carbonato de cal. El mineral es amorfo, de color negro agrisado, i apenas presenta indicio de lustre en la fractura; pero toma con facilidad lustre metálico gris de hierro cuando se frota o se corta con el cuchillo. Su estructura es granuda, de grano pequeño que pasa a terrosa; fractura plana o concoidea, ancha imperfecta; no mancha los dedos; su dureza es 4 . Su carácter notable es su grande tenacidad i su densidad considerable. Se disuelve con facilidad en el amoniaco, dejando apenas 1 a $2 \%$ de residuo arcilloso rojizo.

Las muestras que de este mineral me ha traido el señor Bogan, director de las minas de San Bartolo (Atacama) se hallan atravesadas por venillas mui angostas blancas de espato calizo, i tambien en la masa negra se ven al microscopio puntillas blancas de cal: de manera que el comun del mineral me ha dado:

\begin{tabular}{|l|c|}
\hline óxido negro de cobre $\mathrm{CuO}$ & 76.6 \\
\hline óxido de hierro i de manganesa & 0.9 \\
\hline residuo arcilloso. & 1.4 \\
\hline carbonato de cal (mezcla) & 1.0 \\
\hline agua i pérdida & 3.1 \\
\hline
\end{tabular}

La gran tenacidad de este mineral se debe quizás a que el mineral es algo compresible i en partes recibe impresion de la ulla. Un mineral idéntico con los mismos caracteres esteriores i que no contiene mas que $1 \%$ de sílice se halla en la guia de la mina Bezanilia de los señores Gonzalez i Templeman en el Carrizal. 
COBRE NEGRO FERRUJINOSO (cobre resinita.)- Entre los minerales de cobre oxijenados en Chile uno de los mas comunes aunque nunca mui abundante es lo que los mineralojistas alemanes llaman pechkupfererz [cobre resinita] Este mineral es siempre una mezcla íntima [quizá, una combinacion] de óxido negro, de cobre i de sesquióxido de hierro hidratados; pero su composicion es mui variable i siempre entra en ella una porcion considerable de sílice no enteramente soluble en una disolucion de potasa. El carácter esencial de este mineral es su color negro que a veces pasa a negro de terciopelo i mas o menos de lustre de pez; estructura compacta. El carbonato de amoniaco no disuelve sino las partículas carbonatadas verdes que se hallan con frecuencia mezcladas con la masa negra sin cambiar el color de esta última; pero el ácido nítrico mui diluido disuelve aun sin auxilio de calor la parte oxidada de cobre, dejando el residuo rojo de sesquióxido de hierro i de sílice.

Tres son las clases de minerales de cobre compuestos de sesquióxido de hierro i de óxidos de cobre: 1 los de oxídulo de cobre i de sesquióxido de hierro, hidratados, constituyen mineral aladrillado (ziegeler:); 2 los de protóxido de cobre i sesquióxido de hierro hidratados forman el cobre resinita: 3 los de protóxido de cobre i de sesquióxido de hierro anhidros, probablemente análogos a lo que acabo de describir, bajo el nombre de mineral rojo de la Punta del Cobre.

Pero entre las infinitas variedades de cobre resinita debemos distinguir: unas, que sin duda provienen de la descomposicion de las piritas cobrizas, pues mui a menudo contienen todavía restos de estas últimas diseminadas en la masa de la resiníta i son de color negro mas o menos agrisado. Otras que son mui homojéneas, lustrosas, de negro de terciopelo, sin el menor indicio de partes piritosas, parecen haber tenido oríjen mui distinto de las anteriores.

Un mineral perteneciente a esta segunda categoría i que el señor Carvajal me ha mandado de las minas del desierto de Atacama, es sobre todo notable por su lustre de pez i su homojeneidad, siendo su composicion la siguiente:

\begin{tabular}{|l|r|}
\hline Protóxido de cobre CuO & 13.0 \\
\hline Sesquióxido de hierro & 51.4 \\
\hline Ślice & 13.1 \\
\hline Agua, & 22.5 \\
\hline & 100.0 \\
\hline
\end{tabular}

Este mineral es bastante frájil, infusible, su polvo no cambia de color por la accion del carbonato de amoniaco. Su masa se halla atravesada por venas de malaquita. Grandes cantidades de cobre resinita ferrujinoso se estraen de la mina Bateas, mineral Punta del Cobre, a cuatro leguas de Copiapó, pero la composicion de ellas i el color son mui variables: por lo comun son de color pardo negrusco, de poco lustre, con pequeñas venas de malaquita; contiene algo de pirita cobriza i pasan en hondura a minerales piritosos. Contienen siempre dósis considerable de sílice i de agua. Una variedad de este mineral analizada en el laboratorio del Instituto por los señores Cortez i Sotomayor dío 25.2 de óxido de cobre 46.7 de sesquióxido de hierro, 8.7 de sílice i 16.2 de agua.

COBRE NEGRO COBALTÍFERO- Hállase este rico e interesante mineral en las minas del Cerro Negro, particularmente en la de don José Herrera, en el desierto de Atacama, i debo su conocimiento al injeniero i profesor don J. Carvajal. Dos especies de dicho mineral se distinguen entre diversas muestras que el señor Carvajal me ha mandado.

(a) La primera se parece mucho al cobre resinita cualquiera. Es de color negro que se acerca al de terciopelo; pero su polvo es mas claro, agrisado; su estructura compacta, fractura concoidea ancha imperfecta; poco lustre; algo mas duro que el espato calizo, i tiene cierta tenacidad no mui comun en los cobres resinitas. Se ve atravesada por venas i manchas de malaquita verde.

(b) La segunda especie es de color negro agrisado que en partes tira a ahilado; es blanda i de contestura terrosa. Tisna; i es bastante homojénea, solamente atravesada por unos hilitos de carbonato de cal; en partes salpicada con manchas ocráceas. Al soplete da reaccion de cobalto i en los ácidos deja un residuo abundante de sílice.

Constan estas dos especies de 


\begin{tabular}{|l|r|r|}
\hline & (a) & $(\mathrm{b})$ \\
\hline Protóxido de cobre $\mathrm{CuO}$ & 33.00 & 19.5 \\
\hline de cobalto $\mathrm{CoO}$ & 8.44 & 10.5 \\
\hline Sesquióxido de hierro $\mathrm{F}^{2} \mathrm{O}^{5}$ & 5.50 & 5.0 \\
\hline Ś́lice & 31.04 & 48.5 \\
\hline Agua & 2.00 & 16.0 \\
\hline & 99.98 & 99.5 \\
\hline
\end{tabular}

La composicion de estas especies es tan variable como la de toda clase de cobre negro.

COBRE NEGRO CON MANGANESA.- Esta especie, ya conocida en las minas de cobre de las provincias de Atacama i de Coquimbo, se ha descubierto en cantidades mucho mas considerables en la provincia de Santiago en la mina llamada Las Canales, mineral del Carmen, departamento de Rancagua.

El cobre negro manganesiano de esta mina forma, unas veces, venas mui irregulares en medio de una masa rojiza que contiene cobre nativo i cobre oxidado, otras veces masas irregulares $\mathrm{i}$ papas atravesadas por la malaquita verde. El mineral tiene todos los caractéres de cobre resinita ferrujinoso; lustre de pez mui desigual, estructura compacta, fractura placa o concoidea ancha e imperfecta. Con el ácido clorhídrico da desarrollo de cloro. He hallado para su composicion;

\begin{tabular}{|l|r|}
\hline protóxido de cobre $\mathrm{CuO}$ & 2.9 \\
\hline bióxido de manganesa & 48.9 \\
\hline sesquióxido de hierro & 1.6 \\
\hline sílice» & 7.8 \\
\hline agua & 13.0 \\
\hline carbonato de cal (mezclado). & 5.6 \\
\hline
\end{tabular}

La composicion de este mineral no es menos variable que la de las especies anteriores. Las muestras en que dicho mineral forma masas irregulares en medio de un criadero rojizo son mui hermosas.

Hállase tambien en cantidad considerable cobre negro manganesffero en el mineral de Ojanco, mina Reservada, formando masas terrosas blandas que tiznan i contienen solamente $4.5 \%$ de óxido de cobre, con 7.9 de bióxido de manganesa i mas de $60 \%$ de residuo insoluble.

COBRE SULFÚREO. (Coperina $i$ Chalcosina).- Breithaupt distingue a coperina o cobre sulfúreo hexagonal, de la chalcosina o cobre sulfúreo lromboidal. Aquella forma con frecuencia gemelos dobles, triples i cuádruplos, lleva cruceros paralelos a la base, tiene Dur. 3 a 4,. ps. 5,5. a 5.6, color gris de plomo oscuro mas claro que de la chalcosina, i mui a menudo se cubre de malaquita verde. Breithaupt opina que la coperina es mas comun que la chalcosina i entre las localidades en que se halla la coperina cita Yka, cerda de Huacho en el Perú (Berg,. u. Hutten. Zeit. 1863, 33-34). En Chile quizás las variedades de estructura hojosa, que son por lo comun mas claras i casi siempre cubiertas de malaquita pertenecen a la especie hexagonal i las variedades de estructura granuda de color mas oscuro a la especie romboidal. Últimamente se halló cobre sulfureo cristalizado en prismas romboidales, oblicuos con cruceros paralelos a la base i caras del prisma rayadas a lo largo, en las minas de Cerro Blanco (Copiapó) con pirita cobriza cristalizada i cristal de roca.

Ver texto completo en: www.revistas.uchile.cl 